\title{
31. Game Production Logics at Work: Convergence and Divergence
}

\author{
Aphra Kerr
}

\begin{abstract}
The digital games industry has seen some significant changes in the past ten years, marked by the rise of mobile and free to play games. This chapter discusses production and work in the games industry by exploring some of the similarities and differences between digital games and other cultural and creative industries, examining the emergence of new occupational categories, and investigating the persistence of old inequalities.
\end{abstract}

\section{Introduction}

The digital games industry works hard to present itself as significant in revenue terms, and innovative in technological terms. As game researchers start to gather independent data we have a better basis from which to evaluate these claims. Since the early part of this decade a number of industrial and production changes have become evident. As in other media industries, the digital games industry has shifted from the production of material goods to the provision of digital services. Industry data now indicates that digital revenues are exceeding material revenues in some markets - in the American market this trend appeared around 2012. In an industry worth more than $\$ 100$ billion globally the most rapidly growing segments are online and mobile. More significantly, new business models have emerged - like free to play - and advertising has been growing as a source of revenue (NewZoo, 2016). These shifts have led to new market entrants, including digital distribution companies from outside of the games industry and from different parts of the world. It has also meant that new occupations have been created that either did not exist before, or existed in highly informal ways.

It is tempting to point to these trends as indicating radical technological innovation in the digital games industry. It is all too easy to fall into an uncritical technological determinism - that companies, workers, and players must change in accordance with technological innovation. Yet, histories of media and technology studies more generally would caution against such an approach. My research conducted over roughly two decades on the digital games industry has pointed to some surprising similarities to other media industries and the persistence of certain inequalities in the access to and performance of work in digital games. 
This chapter focuses on three aspects of production and work in the digital games industry. Firstly, it explores some of the similarities and differences between the digital games industry and other creative and cultural industries in their production logics. Secondly, it examines the data on work in the games industry and especially the emergence of new occupational categories and the persistence of old inequalities. Finally, we discuss some of the challenges and opportunities that the industry faces.

\section{Understanding the digital games industry}

The top-selling games in the last few years include Call of Duty: World War II (Activision, 2017), NBA 2 K18 (Take Two, 2017), The Legend of Zelda: Breath of the Wild (Nintendo, 2017), and Clash ofClans (SuperCell, 2012). Even if you have never heard of these games, it is instructive to note that they are mostly produced in North America and Europe with the exception of Nintendo's Zelda franchise. Just as the industry produces a diverse range of games, they can also be played on a range of technologies: from consoles, computers, and mobile phones to watches. Many digital games are now designed to be 'cross platform' from launch. The starting point for understanding this industry, then, is to appreciate that the market, industrial, and organizational structures are diverse - even if the underlying technologies are all digital. While we have technological convergence, at the same time we have other forms of market and organizational divergence. The GAFA intermediaries (Google, Apple, Facebook, and Amazon) have become significant in terms of digital distribution of social and mobile games in the last decade. They have been joined by Chinese companies like Tencent. The 'legacy' game publishers like Microsoft, Sony, Nintendo, Activision Blizzard, and Electronic Arts have responded by purchasing successful social and mobile game development start-ups and expanding into digital distribution.

A useful way to connect industrial and organizational changes in cultural production to work practices in the digital games industry is the production logics approach. This approach also enables us to compare and contrast the digital games industry to existing creative and cultural industries. The production logics approach has a long lineage, and across the cultural industries a number of different production logics have been identified. Raymond Williams (1974) identified flow as a core characteristic of the production and distribution of television, indicating a constant stream of serialized products. Bernard Miège (1987) subsequently identified five logics across the cultural industries: editorial, flow, press, live entertainment, and electronic information. In an era when digital games were mostly sold on cassettes through retail outlets, he mentions that 'videogame inventors' were part of the 
electronic information logic but moving towards the editorial logic with salaried workers and royalties.

For Miège, each production logic is based on five characteristics: the economic value chain, the dominant power brokers, the creative workers/professions, the revenue stream, and the overall market structure. While production logics are dependent on the state of technology at a given moment, they do not list technology as a key characteristic. So, for example, in 1989, in Europe, the dominant production logic for broadcasting was the flow logic. Applying the production logics approach we can identify that its economic value chain included television stations as producers and distributors, who were also the dominant power brokers and gatekeepers. The creative workers were mostly full time employees of the television stations, and the dominant revenue streams were indirect via the licence fee. The dominant market structure was mass market. The key challenges in this logic were to build audience loyalty and ensure a continuous stream of content. Scheduling was a key distinguishing feature.

Some minor adjustments to these logics have been made: a club logic was introduced to capture new subscription based content services, and authors argued about the development of an online portal logic (Winseck \& Jin, 2011; Miège, 2011). Regardless, the big three of editorial, press, and flow dominated in the cultural industries for years.

How might these five logics relate to digital games? In my first book on the digital games industry, published in 2006, I noted how the production of large console and personal computer games (triple-A games in industry parlance) largely conformed to Miège's editorial logic (Kerr, 2006). Interviews with developers all discussed pitching ideas to publishers, securing a publishing deal to make their game, and receiving royalties after launch. The console segment of the games industry was highly vertically integrated and revenues were based on mass market unit sales. It all sounded very familiar to someone who had studied the broader cultural industries.

Massively multiplayer online games like World of Warcraft were significantly different. Development required an industrialized form of production by a diverse team of creative workers, and the subscription services required ongoing content development to keep subscribers challenged and paying. The organization of production was similar to traditional broadcast television or radio - the flow production logic. In the mid-200os, a nascent market in small games for mobile phones existed, but the market structure was uncertain, the distribution system fragmented, and the available technologies lacked standardization. The task of 'porting' a mobile game to hundreds of mobile handsets was a significant barrier to growth. Few game companies were attracted to the creative and financial challenges of the mobile market. The editorial and flow logics could be identified as dominant production logics in digital games, as elsewhere. 
Only ten years later things have evolved significantly. The editorial logic continues to exist in games. MMOGs have evolved in their payment systems but the flow logic contributes to exist. Interestingly, a performance logic has grown strongly in games, and is based around both live eSports and mediated game streaming (Taylor, 2015). Both amateur and professional game players work to make a living in live game play and emerging competition structures modelled on physical sports and broadcast television conventions exist, particularly in the US and in parts of Asia. In addition, new 'club' type services had emerged in the games market with players able to log in to a subscription service and select from a number of contemporary and historical games to play 'in the cloud'. These have been somewhat stymied by the quality of broadband infrastructures in many countries, and thus have been slow to grow. The club logic is sometimes combined with the editorial logic.

Perhaps the most significant shift, however, has been the rise of the Android and Apple digital distribution systems, associated open source tools, and the 'free to play' business model. In my 2017 book on the global games industry, I detail the influence of what can be called a new 'platform' logic, which brings together technological, industrial, creative, and development shifts in the industry (Kerr, 2017). Initially, Facebook was the main distribution platform and social network games were able to work synergistically with the social networking services to promote their games. The emergence of smartphones and the development of alternative digital online retailers with relatively short approval timeframes and standardized hardware and software technologies opened up a new range of creative possibilities for amateurs and professionals. By 2017, indirect forms of revenue had become the norm and 'free to play' had become the dominant business model. Game developers had to rethink elements of their game designs to adapt both to the dominant platforms and to build in-game forms of monetization. Developers were able to access new markets working within this production logic but competition was high and marketing budgets began to grow exponentially.

The central brokers in the platform logic are often technology companies from outside of the games industry and they are capturing a significant share of the economic value created. Companies like Android's Google Play and Apple's App Store take, on average, 30 per cent of upfront or recurring revenues in return for access to their services. Other distribution platforms exist in Asian markets. Nevertheless, the fastest growing segment of the games industry in terms of revenue over the past decade has been mobile games. Companies with less than $5^{0}$ employees have been making revenues to rival their much larger counterparts. Start-up companies like Zynga from America and Supercell from Finland became overnight successes and targets for acquisition by established Japanese, Chinese, and North American game companies. The Swedish company King, who developed the Candy Crush games, was bought by Activision Blizzard in 2016 for $\$ 5.6$ billion. Most of their games are free 
to download and they make their money from advertising and microtransactions (Nieborg, 2015). Later, Tencent bought Supercell for $\$ 8.6$ billion. Tencent also owns Riot (League of Legends) and a share of Activision Blizzard.

Tencent dominates the global games industry in terms of revenues, while Apple, Google, and Facebook have entered the top ten publicly quoted companies by revenue. Blockbusters like Call of Duty and Grand Theft Auto continue to be made and continue to rival large Hollywood productions in terms of developer team size, marketing budgets, and revenues. They are the most similar in production and work type processes to legacy media industries. At the same time, much of the growth is in companies operating within a platform logic, exploring new business models like free to play, and creating new forms of work. Overall, the production logics in the digital games industry are heterogeneous and a period of rapid divergence and innovation in the late oos, has now given way to more stable production logics and industrial consolidation.

\section{The passion, precarity, and crunch of game work}

National-level employment data is not available in many countries for the games industry because the industry cuts across many pre-existing industrial sectors. This lack of data has not been helped by the development of difficult to classify social, mobile, and associated types of game companies. What data exists is often provided by industry associations or third-party media sites, and is biased towards the Anglophone countries. Over the past five years, and using a network of international researchers and translators, I collated numerous independent reports on employment in the games industry. I established that South Korea, the US, China, and Japan were the largest direct employers globally of game developers, while in Europe the UK, Germany, and Spain were the largest employers. In addition, one cannot ignore that the industry has significant links to hardware production factories in Asia, Eastern Europe, and Central America (Huntemann \& Aslinger, 2013). While in this chapter I will focus on content and support workers in game production, it must be noted that workers in these hardware production facilities are also a crucial part of the global games industry.

In content production, we can identify a range of creative professions and a hierarchy in terms of prestige and pay, even if this varies from country to country. Most medium- and large-scale development teams incorporate artists, designers, programmers, engineers, audio specialists, and business and management roles. Data from the US, Canada, and the UK has found that managers, audio specialists, and programmers receive the highest average salaries and that audio and programmers according to one survey were over go per cent male (Graft, 2014). By 
far the lowest paid category in these surveys were quality assurance (QA) testers who were paid less than half what managers are paid and are often on part-time contracts. In addition, in more service orientated production logics we are seeing the formalization of new occupations, including live network operations support and community managers. Companies with transnational online communities may also need public policy specialists.

Full-time contracts are the norm for many in the industry who work for medium- to large-scale companies and the use of freelancers is relatively low - this in contrast to most other media industries. Those in highly sought after job categories can command high salaries, travel visas, and healthcare provisions. Nevertheless, employment can be highly volatile and financial and professional success is based on one's portfolio of completed games, an ability to work in a team, and knowledge of the latest tools. The increasing financialization of the games industry has meant that stock market pressures, company acquisition or poor returns on a game can dictate one's employment status and jeopardize access to bonuses or company stock. Studies in Australia have pointed to the impact of currency fluctuations and the global financial crisis in 2008 on employment in work-for-hire companies (Banks \& Cunningham, 2016). The 2016 International Game Development Association's (IGDA) Developer Satisfaction Survey found that respondents had, on average, 2.2 employers in the previous five years - indicating a high level of volatility for permanent employees.

Those at the lower end of the pay scale have less power to negotiate and less protection. A North American qualitative study argued that game testers are 'precarious workers' and pay is kept low due to the high demand for these positions and the perception that this job is a route into the industry (Bulut, 2015). My own research into community managers in the games industry in Ireland found that while these positions demand significant gaming and cultural knowledge, job advertisements rarely give remuneration details - indeed, some interviewees informed me that their employment contracts forbid them from discussing their remuneration (Kerr, 2016). These roles are also subject to significant volatility. Support workers can be dismissed on short notice if player numbers fail to meet expectations. Since 2008, the most significant growth in Ireland has been in small independent companies. Many are graduate start-ups. There has been no Zynga or Supercell. Working for hire, working with transnational virtual teams, and unpaid work are relatively common. The national social welfare system and access to start-up finance has an important role to play in facilitating small-scale game production. The vibrancy of the local community can also play an important support role, as with the demoscene in Scandinavia (Jørgensen, Sandqvist, \& Sotamaa, 2015).

Much of what has been researched and written about working conditions in the games industry is dominated by responses to surveys from employees in medium 
to large sized companies in the UK and North America. The latest surveys point to ongoing issues with time and project management, which contribute to persistent problems with staff retention in a negative feedback loop. Analysis by Mia Consalvo (2011) of the IGDA Quality of Life survey data identified three persistent issues in the industry: a reliance on crunch time to deliver projects, a reliance on passion for games in recruitment, and a problem with staff retention. These findings are in line with the results from my own research. Our analysis of job advertisements for the recruitment of community managers also found that passion was a much sought after requirement. Indeed, in some advertisements it was listed as a required skill. When examined in more detail, passion was found to perform an important role in hailing cultural insiders. It also tended to result in a reinforcement of highly gendered structures in the industry (Kerr \& Kelleher, 2015).

As in other media industries, we see the intensification of work and non-standard working hours in the digital games industry. While the average working week in the IGDA (2016) survey was 40-44 hours, there appears to be a normalization of crunch time in some companies with over 60 hours a week reported, and much of this overtime uncompensated. A sizable minority (thirteen per cent) reported working over 70 hours a week during crunch. While many might expect some degree of crunch in the run up to a deadline, it is noteworthy that most of these respondents worked in large companies where one might think there would be more professional processes. Also of concern was that respondents to the survey noted that crunch happened a few times a year. Given this pattern, it is not surprising that the profile of respondents to this survey and, indeed, in the industry more generally tends towards the youthful and inexperienced. These working conditions might also be contributing to another significant ongoing challenge for the industry - their problem retaining staff. Survey after survey in the US, Canada, the UK, and Ireland point to a relatively young industry and a lack of experience across teams in project management.

In all the years that I have been researching the industry the figures on gender diversity in the industry have barely improved. The issue is certainly on the agenda of academics and the industry. The IGDA has a Women in Games special interest group (SIGWIG) and there is a Women in Games international group who for over a decade have run conferences and targeted recruitment initiatives. The trade body for the British games industry UK Interactive Entertainment (UKIE) has a diversity initiative and the focus is on promoting the industry as a great place to work to boys and girls. By 2014, the IGDA Developer Satisfaction survey $(n=2,000)$ indicated that up to 22 per cent of those who responded identified as female, which is low compared to other media industries. The 2016 survey ( $\mathrm{n}=1,186$ responses) found that the prototypical game industry worker is a '32-year-old while male with a university degree who lives in North America and who does not have children' 
(IGDA, 2016, p. 7). In the latest Creative Skillset (2015) report on employment across the creative industries in the UK the games industry has the lowest proportion of women at nineteen per cent.

The IGDA survey (2016) stated that a significant majority of respondents noted that 'diversity in the workplace' was important, or very important, but the responses on how companies dealt with discrimination were very mixed and ranged from companies having no policies, to those policies not being enforced. Two issues dominated in terms of what respondents felt drove negative perceptions of the industry: working conditions and sexism in game culture, especially \#GamerGate.

It is difficult to summarize the range of issues bound up in the \#GamerGate controversy and for eloquent accounts see these readings (Mortensen, 2016; Massanari, 2017; Chess \& Shaw, 2015). In short, in 2014 the hashtag gamergate started to circulate and become attached to an online and offline campaign of targeting, harassment, and threats aimed at female game designers, academics, and anyone who defended them. Emerging from a critique of ethics in game journalism, and a discourse that the 'gamer' identity no longer existed, it quickly evolved into a loosely organized networked group who used social media to target anyone who critiqued the dominant forms of masculinity often found in games, game culture, and in the industry. Mortensen describes it as a self-organizing 'swarm', and others have highlighted their connections to the alt right in American politics. Of particular note were their attempts to spread misinformation about games research in academia and the work of female and feminist scholars associated with the Digital Games Research Association (DiGRA). Anyone who was critical of the structure and working conditions of the games industry and the lack of diversity in game representations, could become a target. The period caused harm to some game researchers and game developers, but the actions of gamergaters were also defended by some. The 2016 IGDA Quality of Life Survey indicates that gamergate further fuelled negative views of the games industry in the general public in some countries, and highlighted varying approaches to sexism within the industry itself.

Across the games industry we see a variety of creative roles and like in other media industries we see a hierarchy by occupation, gender, and pay, with business and programming roles able to command higher compensation. Even for those with permanent contracts the financialization of the industry has meant that employment is uncertain and rewards are highly varied. Indeed, financial compensation is not necessarily tied to working hours, or to the success of a game, and in these contexts it is perhaps not surprising that the industry finds it difficult to retain experienced staff and those with caring responsibilities. Most workers enter today with a university qualification, but still many have to take an unpaid internship to learn the latest skills. Most enter with significant levels of gaming capital and sufficient social and economic capital to support their 'passion'. These 
are significant barriers to entry and no doubt reinforce the lack of workplace diversity, especially in core development teams. What is perhaps more surprising is the inability of professional associations and many companies to change existing working conditions and working cultures.

\section{Trends in the global games industry}

Some of the key trends in the digital games industry are shared with other media industries. The first issue has to do with the expanded importance of circulation related processes in digital game production. While marketing and publicity are important in an increasingly crowded mediascape, and community managers play a crucial role in service support and governance, I want to highlight another aspect that might be less visible. Of particular note in the platform logic is the impact that 'datafication' of producer/user relationships is having on processes of design in the free to play business model and the platform logic. The second (and related) issue is that the digital games industry is increasingly subject to local and national data, cultural and political policies. These policies are influencing what types of content get made and where. The final issue has to do with the aforementioned lack of diversity in the workforce and the potential influence this is having on future growth.

The most significant and controversial issue in digital games is how best to apply data science to support free to play revenues without undermining the fun of playing games. If the platform production logic was influenced by the affordances of social media in its first iteration, it is more about the role of data in content design in the current iteration. Advertisements for data analysts who understand the game lifecycle abound. The games industry body TIGA in the UK has asked the UK government to put data analysts on their skills shortage list. This trend is not without its detractors as Whitson (2012) notes, and the resistance of game players to 'loot boxes', for example, signals that in-game mechanics that are linked to microtransactions are contentious. Loot boxes are virtual items that players can find or purchase within a game and that given them prizes and advantages in gameplay. However, they may also be considered a form of gambling, and are actively being investigated by regulators in some countries to see if they should be regulated as gambling.

The use of data and game player metrics is having an impact on the creative autonomy of design teams and there is industry discussion of metric driven design. The production of persistent and intermittent digital game services means that new design elements are tested on real world players often by 'soft launching' in a limited number of markets. It also means that player retention is crucial and that both playing and paying players are carefully monitored. Designing fun to play 
games for the free to play business model requires a careful balance between the quantification of gameplay and the targeted monetization of players.

The status of game companies as data brokers brings new responsibilities in relation to local and regional data and privacy legislation. The General Data Protection Regulation placed new data related responsibilities on all companies holding EU citizen data in mid-2018 and the Children's Online Privacy Protection Act (COPPA) legislation in the US already imposes restrictions in relation to advertising to children. Game companies have been prosecuted in the US for allowing third-party advertising networks to show age and content inappropriate advertising to minors. In addition, game companies who operate transnational services need to conform to other local sensitivities. In China, game companies have to conform to local cultural laws and monitor their game worlds for banned words. Tencent recently introduced additional controls for children in China aged twelve and under in terms of how long they can play mobile games and how much money they can spend. While some well established companies employ staff to attend to the cultural adaptation of the content games to other markets, more recent legislation brings new restrictions on how game companies use player data, attend to user privacy, and control access to their players from third party companies.

Overall, the spatialization of game development has tended not to conform to patterns in other media industries. Game development companies have often located in remote non-capital cities and countries. The relative success of the industry may, however, be contributing to a reshaping of this pattern. National cultural and trade policies aimed at supporting the industry through tax breaks and other non-financial supports have introduced locational competition to the industry. Production tax breaks introduced in France and the UK over the past decade have allowed companies to reduce the costs of labour and production. These policies are based on a 'cultural test'. This means that only game projects that score highly on a list of cultural criteria including, for example, the cultural content and languages offered in the game, links to European cultural heritage, and that locate production in Europe qualify for funding.

Game publishers have been ambivalent as to the desirability of cultural policies which impose restrictions on game content, but, in general, game developers have been much more comfortable being treated as cultural and creative companies (Kerr, 2013). Across the Atlantic generous tax breaks were also introduced in Canada (Quebec, Ontario, British Columbia) and in the US (Georgia, Michigan, Louisiana). Meanwhile, in South Korea, state support is much broader than tax supports and there have been initiatives to promote the playing of games (Jin, 2010). In China, strong state support for indigenous companies and limitations on access to the Chinese market from outside are crucial to understanding the growth of Chinese companies like Tencent (Chung \& Fung, 2013). 
Some of the European and national funding schemes targeted at the games industry are attempting to support both employment and local content production. They are responding to industry figures, which show that control over the economic value and cultural diversity of games has shifted outside of Europe. The top-ten game companies in revenue terms are all North American or Asian. The top-ten companies are large, and getting larger. In 2013, they accounted for almost 44 per cent of global game revenues. While European game companies are highly successful in creating games and games middleware, they are frequently the target of acquisition. The largest European company by revenue is the French company Ubisoft and it is currently fighting against a takeover from the conglomerate Vivendi. There is a sense that European companies have lost control of key publishing roles in the older production logics, and of key intermediary roles in the newer production logics. If ownership of the key digital marketplaces rests with a small number of non-European companies, how do European companies compete in terms of discoverability? What are the algorithms and rules pushing content towards consumers? In the geopolitics of cultural production regional and national policies are now vying with transnational economic priorities and algorithms.

The final consideration that threatens the growth of the games industry is the lack of workplace diversity and the continuing evidence that some game workplaces and cultures are hostile to females and minorities. Clearly, diversity policies focused on awareness raising and promotion of the industry as a place to work will continue to be insufficient if the industry continues to recruit only those who are immersed in a certain type of gamer culture and continues to tolerate inappropriate game culture and workplace behaviour. In the UK survey, one third of women employed in the industry reported experiencing harassment or bullying. It became a clear issue in my interviews with community managers, and female community managers were careful to mask their gender when responding to players in certain games. In a recent survey that I conducted at gamejams in Ireland, 22 per cent had seen, or experienced, gender based discrimination.

\section{Conclusion}

The past decade has seen significant changes in production logics, occupational categories, and the rise and importance of data in the design and circulation of digital games. Over the past decade, the numbers of women who have started to buy and play games, especially social, mobile and online games, has increased exponentially. The number of degree and postgraduate-level courses available in game design and related qualifications in third-level institutions has grown 
significantly and there is clear demand for these courses. Academic researchers have highlighted workplace and in game representation and harassment issues.

In this context, it is perplexing that the focus of attention from professional industry organizations continues to be on awareness raising about the industry and on its problems recruiting staff. The research that we have to date would indicate that recruitment practices and workplace conditions are contributing to these problems. Staff retention issues are linked to working conditions and the precarity of employment. Still, companies and educational programmes often fail to challenge industry stereotypes, workplace inequalities, and discrimination. Academics need to examine more closely the working culture of the games industry. We need to reflect on gaming education and its role in replicating existing practices. And we need to protect those who are doing the research.

\section{Further reading}

- Case: What has changed and what has stayed the same in the global games industry in the past decade - O'Donnell (p. 427)

- Context: An exploration of the rise of the platforms and the powerful role they have in shaping professional media production in the games industry - Nieborg \& Poell (p. 85)

- Contrast: How social inequalities in media work arise and what might be done to tackle them - Eikhof \& Marsden (p. 223)

\section{References}

Banks, J. \& Cunningham, S. (2016). 'Games Production in Australia: Adapting to Precariousness', in M. Curtin \& K. Sanson (eds), Precarious Creativity: Global Media, Local Labor (186-199). University of California Press. Available at https://www.luminosoa.org/site/ books/10.1525/luminos.10/

Bulut, E. (2015). 'Playboring in the Tester Pit: The Convergence of Precarity and the Degradation of Fun in Video Game Testing', Television \& New Media, 16(3), 240-258. doi: $10.1177 / 1527476414525241$.

Chess, S., \& Shaw, A. (2015). 'A Conspiracy of Fishes, or, How We Learned to Stop Worrying About \#GamerGate and Embrace Hegemonic Masculinity', Journal of Broadcasting \& Electronic Media, 59, 208-220. doi: 10.1080/08838151.2014.999917.

Chung, P., \& Fung, A. (2013). 'Internet Development and the Commercialisation of Online Gaming in China', in N. Huntemann \& B. Aslinger (eds), Gaming Globally. Production, Play and Place (232-250). New York: Palgrave Macmillan.

Consalvo, M. (2011). 'Crunched by Passion. Women Game Developers and Workplace Challenges', in Y.B. Kafai, C. Heeter, J. Denner \& J. Y. Sun (eds), Beyond Barbie and Mortal Kombat. New Perspectives on Gender and Gaming (177-190). Cambridge, MA: MIT Press. 
Creative Skillset (2015). Employment Survey. London: Creative Skillset

Graft, K. (2014). ‘Transitions. Salary Survey' (22 July). Retrieved from http://www.gamasutra. com/view/news/221533/Game_Developer_Salary_Survey_2014_The_results_are_in.php.

Huntemann, N. \& Aslinger, B. (eds) (2013). Gaming Globally. Production, Play and Place. New York: Palgrave Macmillan.

IGDA (2016). 'Developer Satisfaction Survey 2016. Summary Report'. Retrieved from http://c. ymcdn.com/sites/www.igda.org/resource/resmgr/files__2016_dss/IGDA_DSS_2016_Summary_Report.pdf.

Jin, D.Y. (2010). Korea's Online Gaming Empire. Cambridge, MA: MIT Press.

Jørgensen, K., Sandqvist, U. \& Sotamaa, O. (2015). 'From Hobbyists to Entrepreneurs: On the Formation of the Nordic Game Industry', Convergence: The International Journal of Research into New Media Technologies. doi: 10.1177/1354856515617853.

Kerr, A. (2006). The Business and Culture of Digital Games: Gamework/Gameplay. London: SAGE Publications.

Kerr, A. (2013). 'Space Wars: The Politics of Games Production in Europe', in N. Huntemann \& B. Aslinger (eds), Gaming Globally. Production, Play and Place (215-231). New York: Palgrave Macmillan.

Kerr, A. (2016). 'Recruitment, Work and Identity in Community Management: Passion, Precarity and Play', in J. Webster \& K. Randle (eds), Virtual Workers and the Global Labour Market (117-135). New York: Palgrave Macmillan.

Kerr, A. (2017). Global Games. Production, Circulation and Policy in the Networked Age. New York: Routledge.

Kerr, A. \& Kelleher, J.D. (2015). 'The Recruitment of Passion and Community in the Service of Capital. Community Managers in the Digital Games Industry', Critical Studies in Media Communication, 32(3), 177-192. doi: 10.1080/15295036.2015.1045005.

Massanari, A. (2017). ‘\#Gamergate and The Fappening: How Reddit’s Algorithm, Governance, and Culture Support Toxic Technocultures', New Media \& Society, 19(3), 329-346. doi: $10.1177 / 1461444815608807$.

Miège, B. (1987). 'The Logics at Work in the New Cultural Industries', Media, Culture and Society, 9(3), 273-289. doi: https://doi.org/10.1177/016344387009003002.

Miège, B. (2011). 'Principal Ongoing Mutations of Cultural and Informational Industries', in D. Winseck \& D.Y.Jin (eds), The Political Economies of Media (51-65). London: Bloomsbury Academic.

Mortensen, T.E. (2016). 'Anger, Fear, and Games: The Long Event of \#GamerGate', Games and Culture. doi: 10.1177/1555412016640408.

NewZoo (2016). 'Top 100 Countries by Revenue' (16 March). Retrieved from https://newzoo. com/insights/rankings/top-10o-countries-by-game-revenues/.

Nieborg, D.B. (2015). 'Crushing Candy: The Free-to-Play Game in Its Connective Commodity Form', Social Media + Society, 1(2). doi:10.1177/2056305115621932. 
Taylor, N. (2015). 'Professional Gaming', in R. Mansell et al. (eds), The International Encyclopedia of Digital Communication and Society. Malden, MA and Oxford: Wiley Blackwell. Whitson, J. (2012). Game Design by Numbers: Instrumental Play and the Quantitative shift in the Digital Game Industry (PhD thesis). Ottowa: Carleton University.

Winseck, D. \& Jin, D.Y. (2011). The Political Economies of Media. The Transformation of the Global Media Industries. London: Bloomsbury. 